Article

\title{
Sensitivity Analysis of Seismic Velocity and Attenuation Variations for Longmaxi Shale during Hydraulic Fracturing Testing in Laboratory
}

\author{
Hongyu Zhai ${ }^{1}$, Xu Chang ${ }^{1, *}$, Yibo Wang ${ }^{1}$, Ziqiu Xue ${ }^{2}$, Xinglin Lei ${ }^{3}$ and Yi Zhang ${ }^{2}$ \\ 1 Key Laboratory of Shale Gas and Geoengineering, Institute of Geology and Geophysics, Chinese Academy \\ of Sciences, Beijing 100029, China; zhaihongyu@hotmail.com (H.Z.); wangyibo@mail.iggcas.ac.cn (Y.W.) \\ 2 Research Institute of Innovative Technology for the Earth (RITE), 9-2 Kizugawadai, Kizu-cho, Soraku-gun, \\ Kyoto 619-0292, Japan; xue@rite.or.jp (Z.X.); zhangyi@rite.or.jp (Y.Z.) \\ 3 Geological Survey of Japan, National Institute of Advanced Industrial Science and Technology (AIST), \\ Central 7, Higashi 1-1, Tsukuba City, Ibaraki 305-8567, Japan; xinglin-lei@aist.go.jp \\ * Correspondence: changxu@mail.iggcas.ac.cn; Tel.: +86-010-8299-8281
}

Received: 31 July 2017; Accepted: 8 September 2017; Published: 13 September 2017

\begin{abstract}
During the hydraulic fracturing procedure in shale-gas exploitation, the poroelastic properties of shale formation can be altered significantly. However, it is difficult to evaluate these variations using microseismic field data. In this study, we conduct a hydro-fracturing experiment using Longmaxi shale, which is a major formation for shale-gas production in China, to simulate the water injection and rock fracturing procedure. The variation of the velocity and attenuation for primary/secondary $(\mathrm{P} / \mathrm{S})$ ultrasonic waves was investigated throughout the entire experimental procedure. The results show that the attenuation is more sensitive to sample rupture than the velocity. However, P-wave attenuation loses sensitivity to the water injection after the fractures are saturated with water. In that case, it is preferable to use S-wave attenuation to identify the opening/closing of the fractures. Based on the experimental results, we can conclude that the variation of the attenuation must be considered during microseismic data processing and interpretation.
\end{abstract}

Keywords: velocity; velocity; attenuation; ultrasonic wave; triaxial compression; hydraulic fracturing; Longmaxi shale

\section{Introduction}

Unconventional oil and gas reservoirs usually exhibit extremely low porosity and permeability. Hydraulic fracturing is the primary exploitation technique used to improve gas/oil extraction efficiency [1]. Further, using microseismic monitoring techniques, engineers can obtain information on fracture type, and evaluate the generation of a fracture network in the sediment [2,3]. During the hydraulic fracturing process, however, the fracture distribution and reservoir physical properties are altered significantly due to thousands of tons of high-pressure water injection $[4,5]$. The variation of $\mathrm{P}$ - and S-wave attenuation will have a significant impact on the quality of microseismic data, especially for the waveform of the S-wave [6]. Besides, most methods of microseismic data processing or inversion do not consider the dynamic variations of petrophysical parameters, i.e., the primary/secondary $(\mathrm{P} / \mathrm{S})$-wave velocity, attenuation, and anisotropy $[7,8]$. Such factors may introduce additional errors to the location results and source mechanism inversion results of microseismic events, and thus should be sufficiently addressed [9]. Furthermore, it is hard to measure the changes using only traditional seismic data, microseismic data, and logging data [10-12].

To determine the physical characteristics of sediment rock, many researchers have implemented petrophysical experiments to compensate for the deficiencies of seismic exploration techniques [13-16]. 
Under those experimental conditions, different sediment pressures, temperatures, and saturation conditions can be simulated, and the rock-sample failure process can be reproduced precisely. Moreover, in recent years, a small number of researchers have begun to utilize synthetic materials to model certain specialized rock structures; this approach is convenient for the investigation of variations in the wave attenuation anisotropy and certain destructive tests $[17,18]$. Following the development of the computed tomography (CT) scanning technique, the internal structure and failure procedure of a sediment rock sample can now be investigated conveniently and accurately [19-21]. On the other hand, many researchers have conducted a large number of experiments to investigate the physical characteristics of different kinds of shale under various stress loading conditions [22,23]. For example, Eagle Ford Shale has strength anisotropy, according to the estimation of shear strength by using an intact sample [24]. Further, there is a direct proportion between the anisotropy of shear wave velocity and effective stress loading in organic-rich shales; and the results indicate that velocity anisotropy is primarily dominated by the oriented shale micro-fabric [25,26]. Moreover, Josh et al. [27] have implemented a workflow for systematic shale characterization in the laboratory using a full suite of nondestructive petrophysical methods. Note that the examination of seismic attenuation properties for shale rock is also an important research direction because the seismic attenuation in shale has strong frequency dependency and anisotropy $[28,29]$. The high clay content is somewhat of a weakness for shale hydraulic fracturing due to the interaction between clay minerals and injected fluid. When more and more fluid is injected into sediment, water transport occurs in the rock matrix and differently-scaled pore spaces can alter the physicochemical properties of a shale reservoir significantly, finally resulting in a noticeable variation of velocity and the attenuation value [30-32].

It is well documented that shale specimens from different areas and formations show significant differences in physical properties. The shale formation in the Sichuan Basin, southwest China, is deposited in an anoxic deep-water environment, whose dispositional environment, mineral constituent and geophysical characteristics have been widely analyzed because of the ongoing development of shale-gas exploitation in China [33-36]. Further, as regards the lower Silurian Longmaxi shale, high levels of quartz and clay minerals generate complex matrix pores, such as organic pores, inter-particle pores and inter-crystalline pores [37]. Utilizing several advanced approaches (field emission scanning electron microscopy (FE-SEM) (JSM-6700F, JEOL USA, Inc., CA, USA), gas adsorption, and helium pycnometry), the complexity of pores structures and the properties of nanoscale pores in Longmaxi shale are identified clearly [38,39]. Also, the relationship between mineral components and dynamic elastic properties of shale rock has been measured using an ultrasonic transmission technique [40]. These research works have enhanced the understanding of Longmaxi shale and improved shale-gas exploitation remarkably in China.

In previous studies, most researchers have mainly focused on the characteristics of Longmaxi shale, such as its brittle mineral content, organic geochemical analysis, internal pore distribution and features of fractures $[35,37,38]$. Only a few researchers have investigated the velocity of P-and S-waves using a traditional uniaxial/triaxial compression experiment [40,41]. According to previous research, the clay content, fracture azimuth and volume density of cracks are the key factors affecting the velocity value. However, these research conclusions do not consider the effect of hydraulic fracturing. In this study, we performed a laboratory hydro-fracturing experiment on a Longmaxi shale sample using a triaxial compression device, an active ultrasonic measurement device, and a CT scanning device. After the test, the internal structures of the fractured shale sample were assessed, and the dynamic changes to ultrasonic P/S-wave velocity and attenuation were quantitatively analyzed. Finally, the sensitivities of velocity and attenuation changes to the hydraulic fracturing were compared. 


\section{Materials and Methods}

\subsection{Sample and Experimental Setup}

One cylindrical shale sample (diameter of $50 \mathrm{~mm}$ and length of $125 \mathrm{~mm}$ ), from the Lower Silurian Longmaxi formation in the Sichuan basin, China, was prepared for the hydraulic fracturing experiment. Before the test, a medical X-ray CT scanning equipment (Aquilion ONE TSX 301A, Toshiba Medical Systems Corp., Kyoto, Japan, belonging to RITE) was utilized to analyze the bedding structure and orientation of pre-existing fractures generated by drilling and drying. According to the sample scanning profiles (Figure 1), a major fracture propagated along the bedding plane and penetrated the central axial position completely. Then a cylindrical coordinate system was applied to the model the sample, with the origin located at the sample center. Twenty piezoelectric transducers (PZTs) and four strain gauges were mounted on the sample surface; Figure 2 shows their positions on the two dimension (2D) unfolding surface. The central bedding planes were parallel to the axial direction and can be seen to strike along the $0^{\circ} \rightarrow 180^{\circ}$ direction. All the PZT sensors, which had a $2 \mathrm{MHz}$ intrinsic frequency, were used to transmit and receive $\mathrm{P} / \mathrm{S}$ ultrasonic signals for velocity measurement along multi-ray paths during the experiment. A total of 20 PZTs were glued on the sample surface, with those labeled Nos. 1-12 (indicated by small orange "+" symbols in Figure 2) being P-wave sensors and those labeled Nos. 13-20 (purple arrows in Figure 2) being S-wave sensors. The horizontal and vertical purple arrows represent the polarization direction of S-wave is parallel with radial direction (SH) and axial orientation (SV) of the sample, respectively. The label number of the sensors used for the source were colored red (Nos. 7-12 and 17-20); and the remaining sensors were utilized for signal reception. Note that Nos. 7-12 were P-wave sensors, while Nos. 17-20 were S-wave sensors. Due to different polarization attributes, S-wave sensors were divided into SH (Nos. 14, 16, 18, 20) and SV (Nos. 13, 15, 17, 19) sensors respectively.

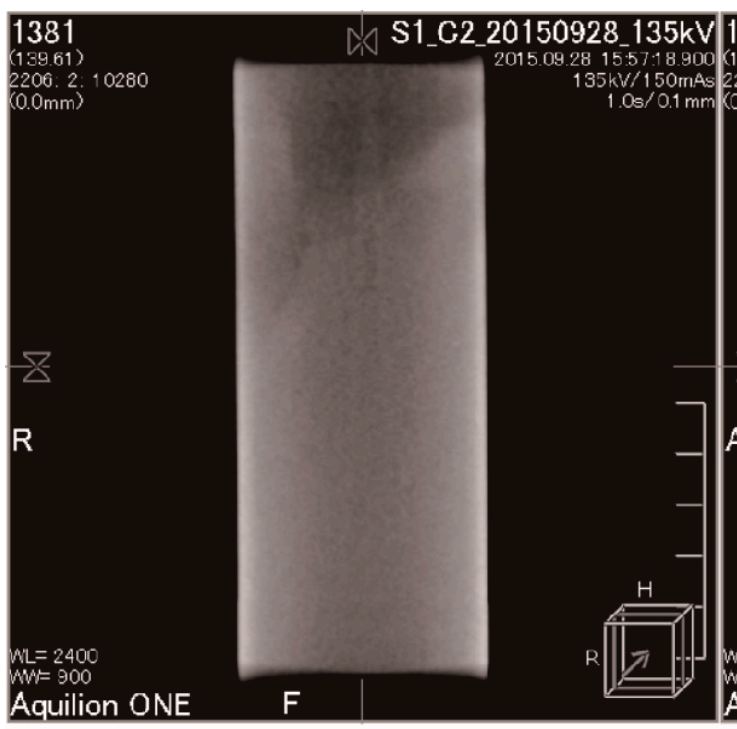

(a)

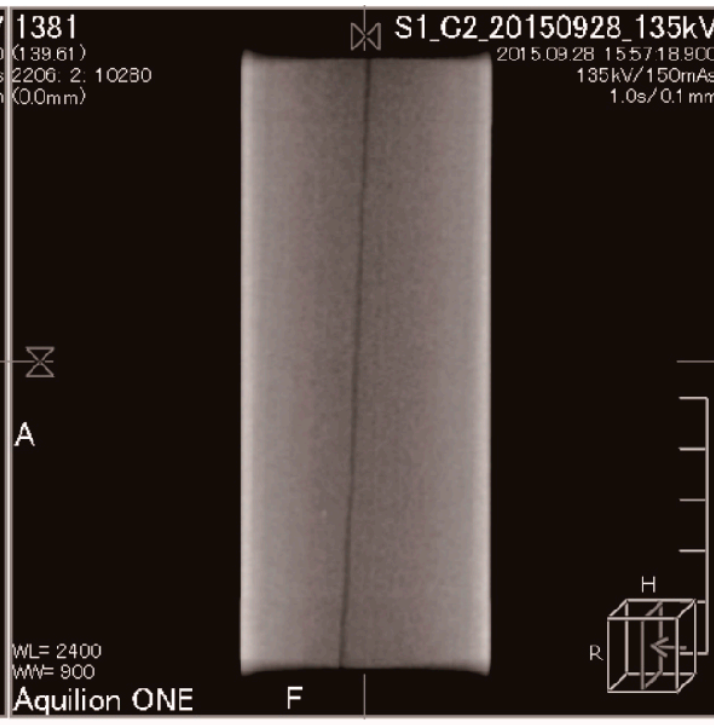

(b)

Figure 1. X-ray CT images of the shale sample along two perpendicular scanning directions (indicated in the bottom right corner of each image) in the central position. $(\mathbf{a}, \mathbf{b})$ Scanning slices are parallel with and perpendicular to the bedding planes, respectively. 


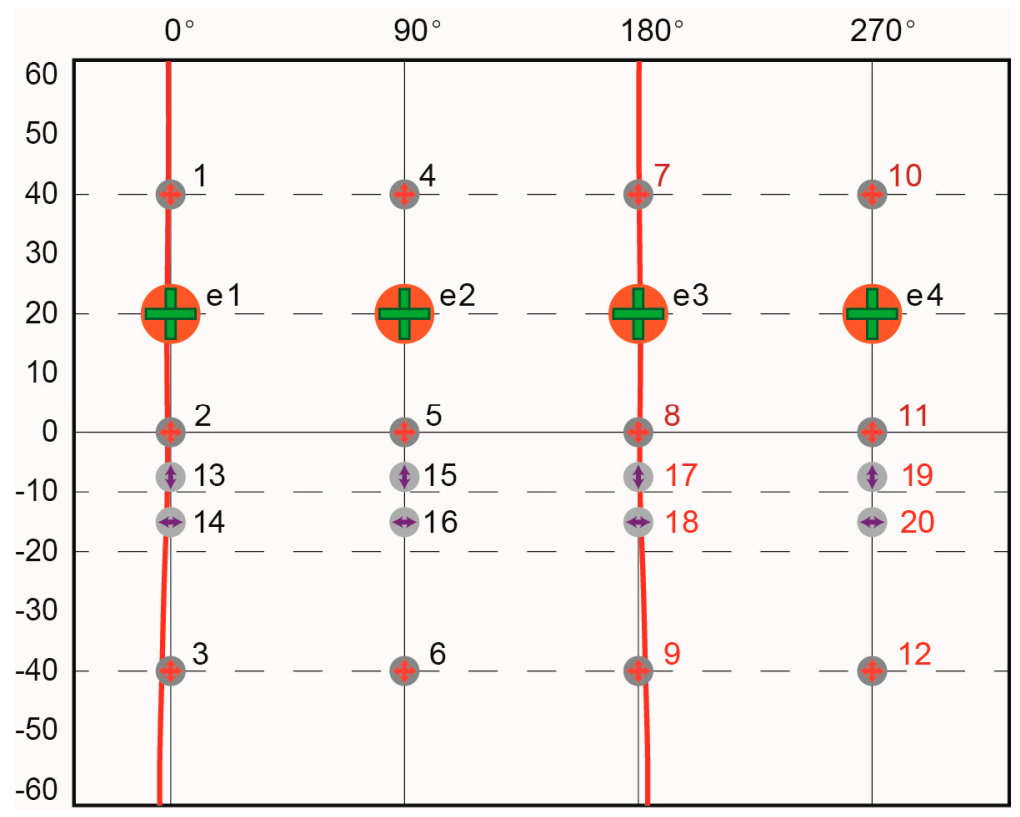

Figure 2. The configuration of PZTs and strain gauges mounted on the sample surface. The strain gauges are labeled e1-e4 and the horizontal and vertical strain can be measured for each strain gauge. The P-and S-wave sensors are labeled 1-12 (orange "+" symbols) and 13-20 (purple arrows), respectively. The red line indicates the pre-existing fracture generated during drying.

Before the test, a series of procedures were prepared (Figure 3), and the specimen was sealed by silicone coat to isolate the test sample from the confining oil. Then a triaxial compression system with a capacity of 2000 tons belonging to the Geological Survey of Japan [42] was utilized to load stress and simulate the hydraulic fracturing procedure (Figure 4). As the figure shows, axial stress came from the press machine, and confining pressure came from the high-pressure pump. During the hydraulic fracturing, water injection was implemented from the top and bottom of the sample by two high-pressure syringe pumps (Pump A and B). Also, we used the original fractures as water injection channels without drilling additional holes. During the test, the ultrasonic P/S wave signal was recorded using the high-speed multi-channel acoustic emission (AE) measuring system [21].

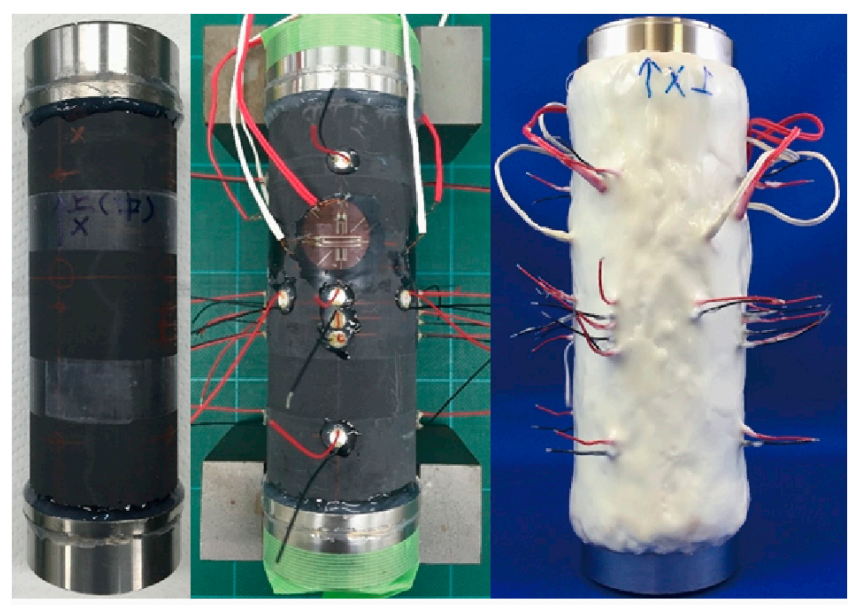

(a)

(b)

(c)

Figure 3. Preparing procedure for the shale sample before the hydraulic fracturing test. (a) Mount the end pieces; (b) Install the PZT sensors and strain gauges according to Figure 2; (c) Seal the sample using a silicone coat. 


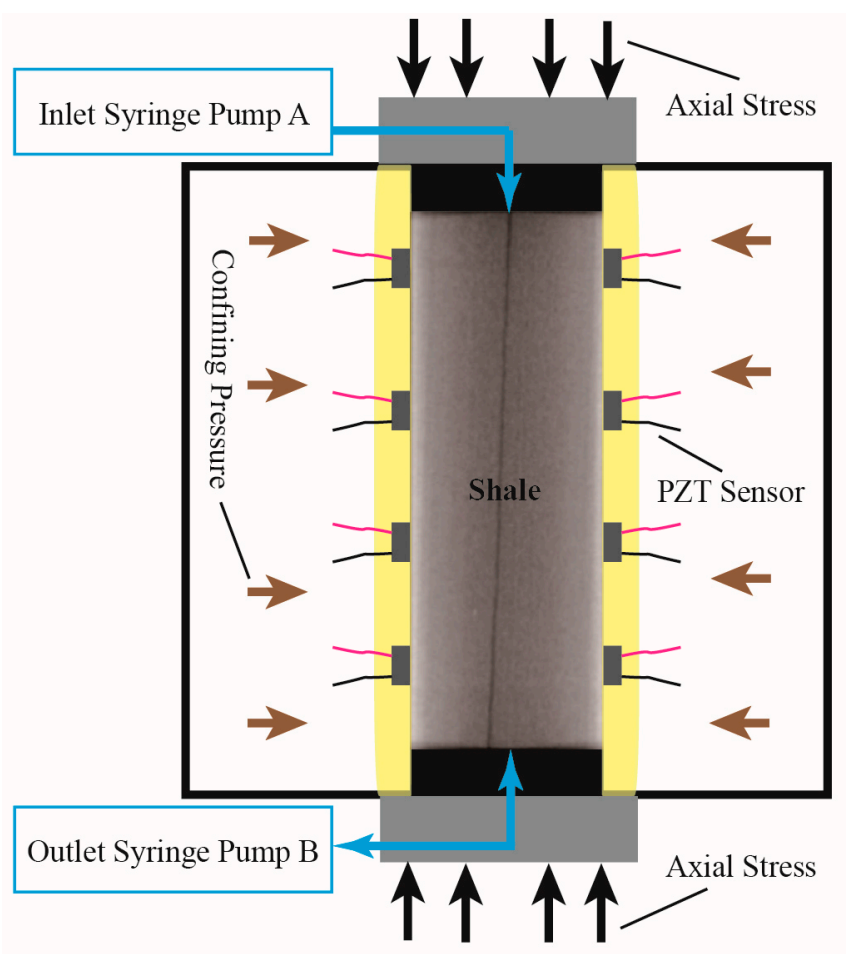

Figure 4. Schematic of the experimental setup for P- and S-wave velocity and attenuation measurement under a triaxial compression conditions.

To simulate the hydraulic fracturing, a complex stress loading and water injection procedure was employed, and the corresponding strain variations were recorded by four strain gauges (Figure 5). In the beginning, water was injected into the sample from pump A and B, and there was a positive pressure difference between the two pumps. When the pre-existing fracture was stimulated, or new fractures were produced due to continuous ascending injection pressure, the injected water from pump A would pass through the sample and be stored in pump B. As shown in Figure 5, the inlet (yellow line) and outlet (purple line) pressures represent the water pressure at the top and bottom of the sample respectively. Finally, the whole experiment can be divided into four stages due to the specific stress loading and water injecting procedure, and stage iii and iv are the main hydraulic fracturing stages.

Stage i: Confining pressure was slowly increased to $40 \mathrm{MPa}$, and inlet pressure simultaneously rose to $10 \mathrm{MPa}$ to avoid the pre-existing fracture's absolute closing. As shown in Figure 5c, the variation of $\mathrm{e} 3_{\mathrm{H}}$ in this stage indicates that the pre-existing fracture showed firstly closing and subsequently opening behaviors. At first, the fracture was closing gradually due to increasing confining pressure. Then, at the end of this stage, the closing trend stopped, and the fracture turned to open as a result of pore-pressure diffusion.

Stage ii: Axial stress was linearly loaded to $150 \mathrm{MPa}$, while the inlet and outlet pressures were rapidly increased to 22 and $20 \mathrm{MPa}$, respectively. Then, the water injection pressures were kept constant throughout the remainder of this stage. In this stage, the test sample had an obvious dilatancy, which could be identified from the variation of the axial and horizontal strain.

Stage iii: The inlet pressure was gradually increased to approximately $35 \mathrm{MPa}$ for inducing hydraulic fracturing. The outlet pressure remained stable at this stage. However, the sample did not have apparent deformation until the inlet pressure reached $32 \mathrm{MPa}$ (after $9.8 \mathrm{~h}$ ). As shown in Figure $6 c, e$, the sample deformation appeared mainly along the axial direction, and the pre-existing fracture had a further expansion as well (corresponding to the negative 
increase of the $\mathrm{e} 3_{\mathrm{H}}$ value). Then, the hydraulic fracturing process widely accelerated after the inlet pressure reached $35 \mathrm{MPa}$.

Stage iv: The outlet valve was closed to simulate an undrained condition. Then gradually increasing pressure on the outlet side was observed, indicating a breakthrough of water from the inlet side (Figure $6 \mathrm{~b}$ ). From the zoomed-in view of this stage, we found that the sample had suffered further cracking than in stage iii (Figure $6 \mathrm{~d}, \mathrm{f}$ ). When the $\mathrm{f}_{\mathrm{o}}$ reached $25 \mathrm{MPa}$ (after $10.3 \mathrm{~h}$ ), the negative increasing rate of $\mathrm{e} 3_{\mathrm{H}}$ showed two accelerated steps, which indicated that the swift opening had occurred firstly around the pre-existing fracture. When the $f_{o}$ value closed to $30 \mathrm{MPa}$, a comprehensive fracturing of the sample had been generated. From the change range of monitored strain value (Figure $6 \mathrm{~d}$ ), the final fracturing process only lasted about $4.5 \mathrm{~min}$. Then the experiment was stopped due to the visible descending of loading stress and injection pressure.

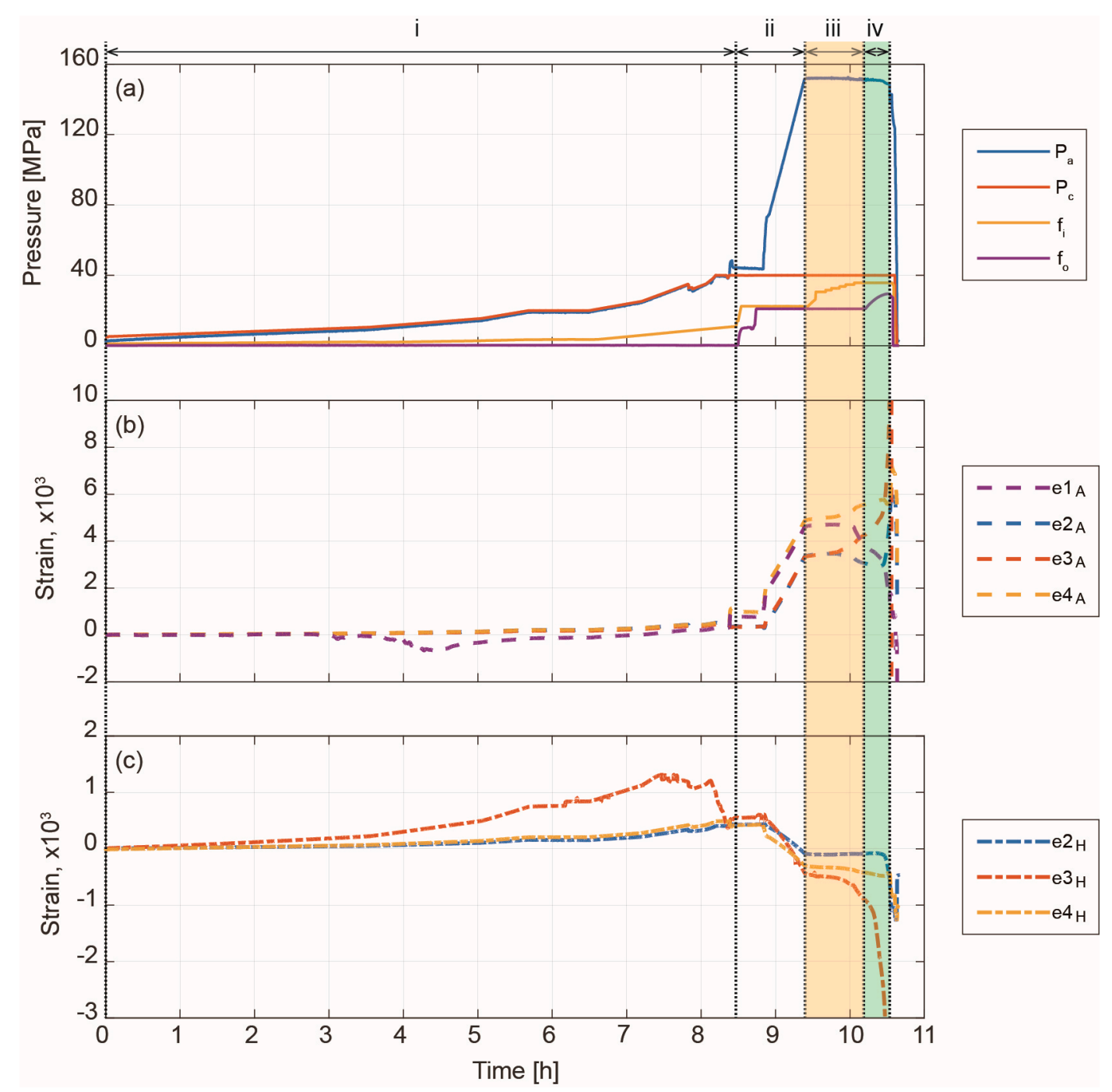

Figure 5. Stress loading and water injection processes for the sample, and the plots of strain curves. (a) Numbers i-iv indicate loading and injection stages. $\mathrm{P}_{\mathrm{a}}$ and $\mathrm{P}_{\mathrm{c}}$ represent axial stress and confining pressure, respectively. $f_{i}$ and $f_{o}$ represent injection pressure from pump A and pump $B$, respectively; (b) Axial strains monitored by sensor e1-e4; (c) Circumferential strains monitored by sensor e2-e4, and the $\mathrm{e} 1_{\mathrm{H}}$ was broken or shorted before the test. 

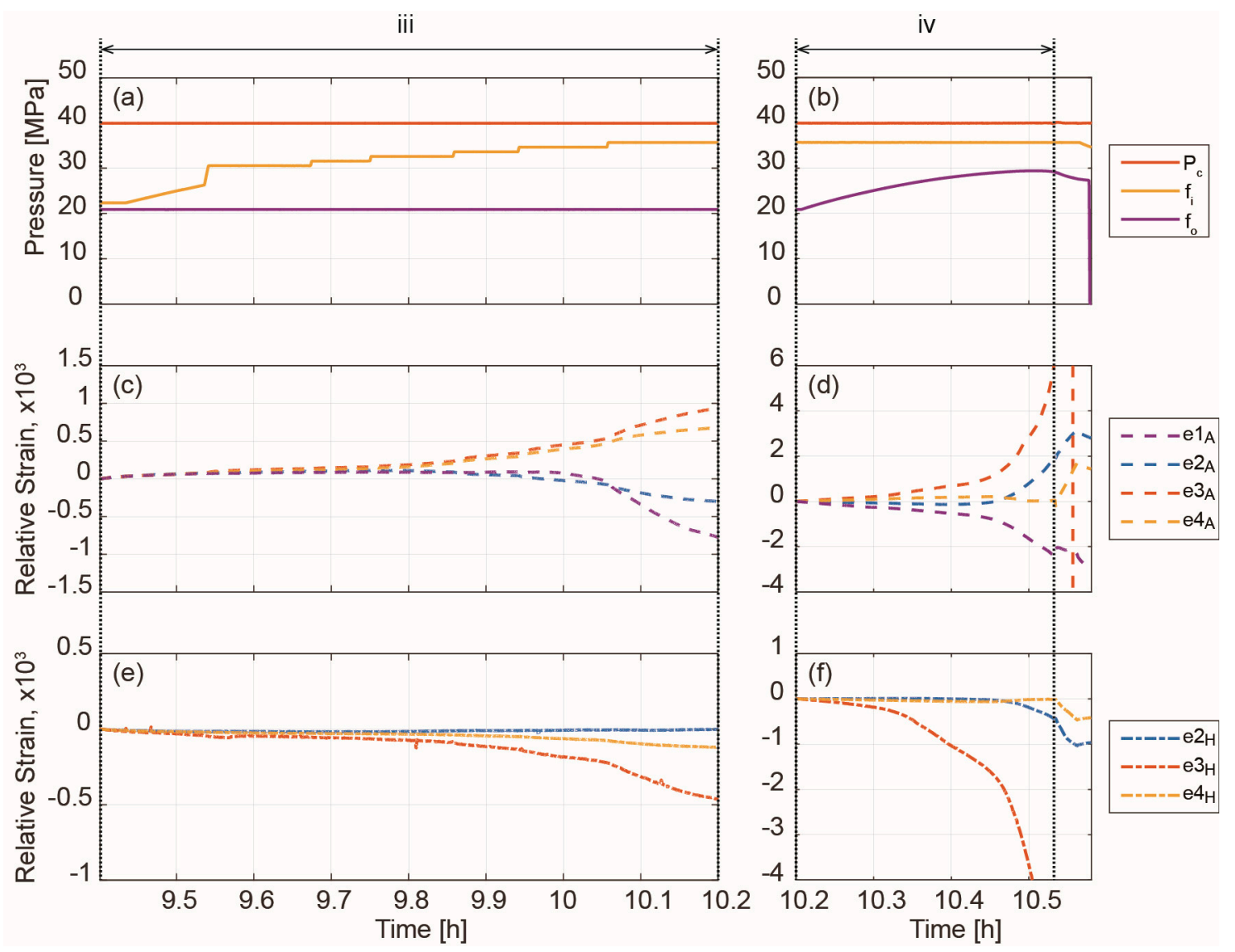

Figure 6. Zoomed-in view of the test during stage iii and iv, respectively. (a,b) Plots of loading stress and injection pressure; (c,d) Relative axial strain curves; $(\mathbf{e}, \mathbf{f})$ Relative circumferential strain curves.

\subsection{Data Processing}

After the experiment, we acquired a considerable amount of ultrasonic P/S-waveform data along different wave traveling paths. Then, the ultrasonic wave velocity and attenuation were calculated along several specific traveling paths, using first-arrival time and waveform information of the $\mathrm{P} / \mathrm{S}$ head wave and the corresponding positions of all PZT sensors. When the PZT sensor No. 11 was used as a source, one set of P-wave signals received from sensor No. 5 in a different measuring time is shown in Figure 7a as an example. With the increasing serial number, the energy and arrival time of the head P-wave appeared evidently to be descending, which indicated that more and more fractures had been generated due to hydraulic fracturing. Meanwhile, we could note a series of accurate first-arrival times (as the red arrows show) due to the high signal-to-noise ratio. Finally, the calculated velocity was exact and credible as well. As illustrated in Figure 2, the velocity and attenuation of the P waves were calculated along three specific paths $(\perp-\mathrm{U}, \perp-\mathrm{M}, \perp-\mathrm{L})$. And for the $\mathrm{SH}$ and $\mathrm{SV}$ waves, the same calculations were conducted in two directions, parallel with and perpendicular to the fracture plane (//-SH, / /-SV, $\perp-\mathrm{SH}, \perp-\mathrm{SV})$.

In this study, the reciprocals of $P$ - and $S$-wave quality factors $\left(Q_{P}^{-1}\right.$ and $Q_{S}^{-1}$, respectively) were used to quantify the attenuation feature. We utilized the widely employed $Q$-value estimation method, i.e., the spectral ratio (SR) method $[13,29,43]$, to calculate $Q_{P}^{-1}$ and $Q_{S}^{-1}$. According to the SR method, a wave traveling in an attenuated medium can be expressed as:

$$
B_{1}\left(f, t_{1}\right)=B_{0}\left(f, t_{0}\right) \exp \left(\frac{-\pi f \Delta t}{Q}\right), \Delta t=t_{1}-t_{0}
$$


where $B_{0}\left(f, t_{0}\right)$ and $B_{1}\left(f, t_{1}\right)$ are reference (traveling in a standard aluminum sample) and attenuated (traveling in a shale sample) wave spectra, respectively (Figure $7 \mathrm{~b}$ ). $f$ is frequency, and $\Delta t$ is travel time. As Figure $7 \mathrm{~b}$ shows, the main frequency of the attenuated wave descended observably because of energy dispersion and absorption. The more new fractures that were created, the stronger the attenuation effects that were suffered by the P- and S-wave. Then, Equation (1) can be written as:

$$
S R(f)=\ln \left(\frac{B_{1}}{B_{0}}\right)=\alpha f+C, \alpha=\frac{-\pi \Delta t}{Q}
$$

where $C$ is a constant. Finally, the slope $(\alpha)$ of the best-fitting line was calculated using the $S R(f)$ data, and the corresponding $Q$ value was estimated. In order to improve the precision of the estimated $Q$ value, an effective frequency band, which was determined according to the frequency distribution of the dominant energy from $B_{0}\left(f, t_{0}\right)$ and $B_{1}\left(f, t_{1}\right)$, was applied to filter the spectral ratio (Figure $7 \mathrm{c}$ ).

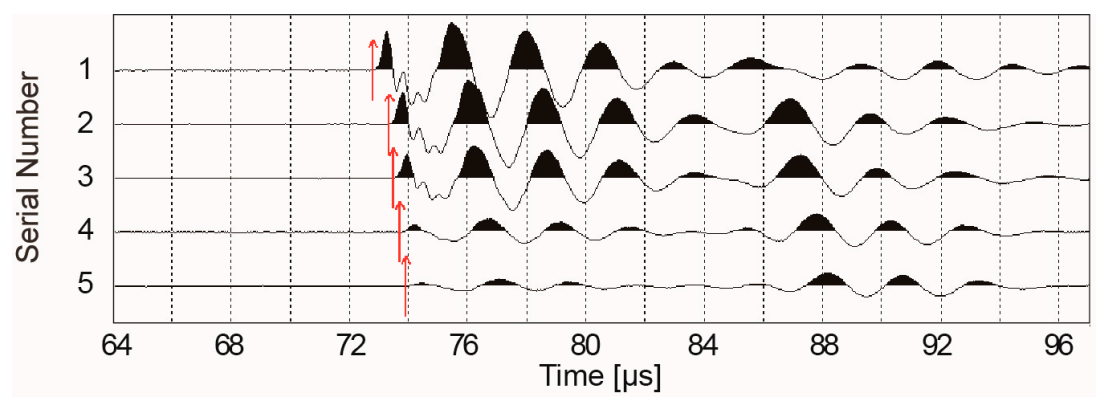

(a)

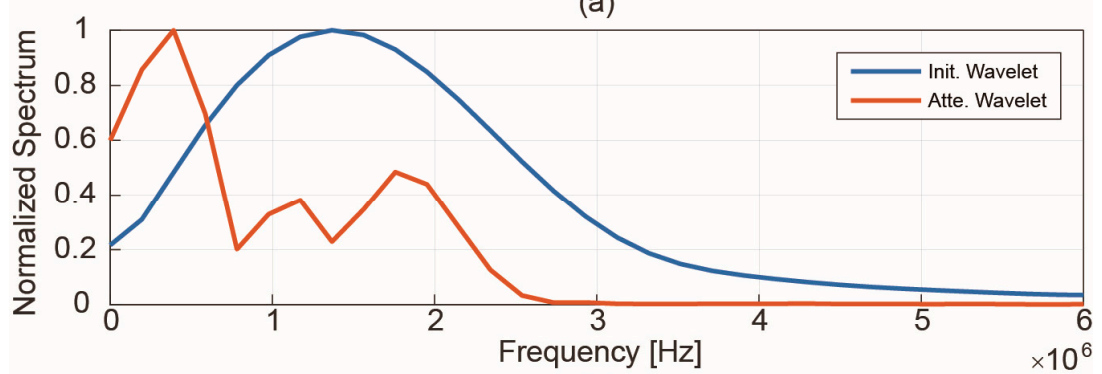

(b)

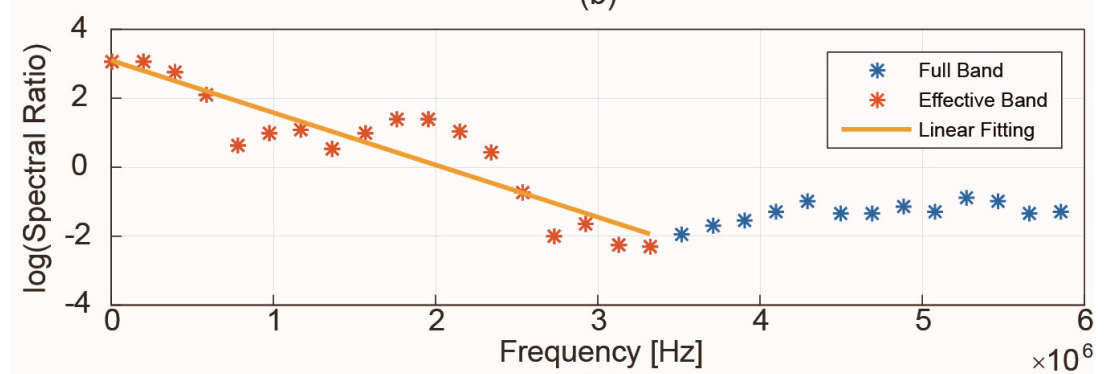

(c)

Figure 7. Example of received ultrasonic wave signals and spectral ratio calculation of the quality factor. (a) A set of P-wave signals received at sensor No. 5 and transmitted from sensor No. 11; (b) Normalized spectrum example of the initial unattenuated $\mathrm{P}$-waveform and one attenuated first-arrival P-waveform; (c) Spectral ratio calculation of $Q$ by using the effective frequency band.

\section{Basic Assessment of Hydro-Fracturing Effects}

Because of the high clay content $(36.5 \%)$ of our sample and strong water reaction, only a few $\mathrm{AE}$ signals (tens of AEs) were recorded during the stress loading and dynamic breaking process. However, hundreds of induced AEs (634 AEs) were recorded within a few seconds at the end of the unloading stage. After hydro-fracturing, the sample was scanned again using the same X-ray CT 
equipment. Based on the scanning slices (Figure 8), a basic assessment of the hydro-fractures was conducted. Compared with Figure 1, there were many new fractures that had been generated after the hydro-fracturing, and one primary fracture penetrated the sample along the diagonal direction. Besides, many secondary fractures penetrated the bedding plane, generating a complex fracture net.

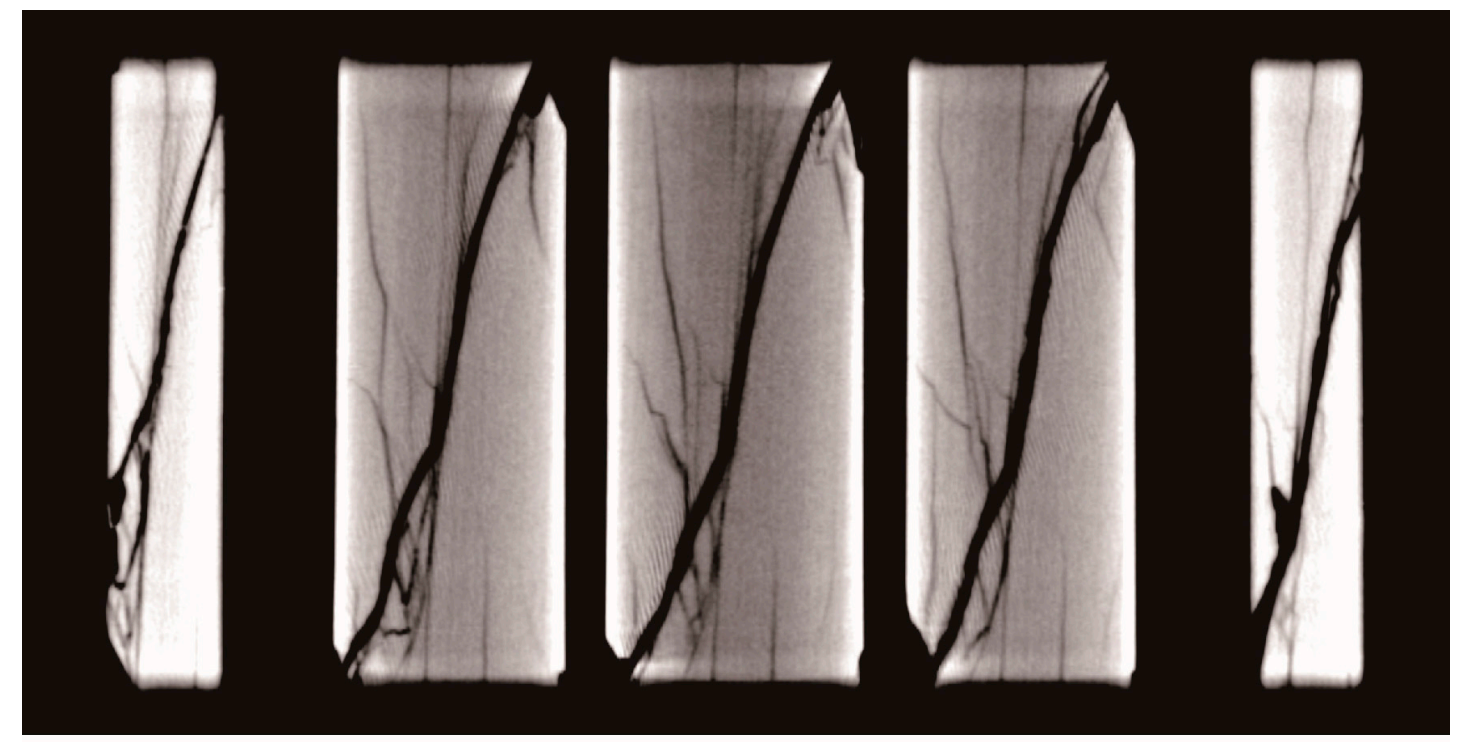

(a)

(b)

(c)

(d)

(e)

Figure 8. CT scanning slices of the sample along the axial direction and normal to the bedding plane. The labels (a-e) indicate the position of selected slices from $\mathrm{x}=-22.5 \mathrm{~mm}$ to $\mathrm{x}=22.5 \mathrm{~mm}$ with 11 mm intervals.

Such a fracture net can affect the traveling of $\mathrm{P} / \mathrm{S}$ waves extraordinarily. According to Figure 9, the measured velocity and attenuation along different traveling paths suffered different levels of influence. Therefore, it is essential to quantitatively analyze the variation of ultrasonic wave velocity and attenuation for evaluating the hydraulic fracturing effects. Considering the distribution of new fractures, we primarily investigated the P- and S-wave velocity and attenuation in two directions, i.e., parallel and vertical to the fracture plane, which was labeled in this paper by the // and $\perp$ symbols, respectively (Figure 9). Firstly, for the P-wave, the measurements at three positions were conducted along one direction where the ray trace (orange dash line) is vertical to the bedding layers in the upper the $(\mathrm{U})$, middle $(\mathrm{M})$, and lower $(\mathrm{L})$ parts of the sample. The sequence numbers of the P- wave sources and receiving sensors from the upper to lower positions are Nos. 10-12 and Nos. 4-6, respectively. Secondly, for the S-wave, a similar measurement was performed at the lower-middle part of the sample along two directions (parallel with and normal to the bedding planes) using the data received from the SV (Nos. 13 and 15) and SH (Nos. 14 and 16) sensors.

\subsection{Velocity vs. Injection Pressure}

In this section, we mainly focus on the velocity variation of the ultrasonic P/S-waves as a function of injection pressure during experimental stages iii and iv. Since the new-born fractures are dominated by the bedding plane, $v_{P}$ value was measured only along the radial direction which was also perpendicular to the bedding plane. Firstly, the $v_{P}$ kept stable $(4 \mathrm{~km} / \mathrm{s})$ at three measuring positions during stage iii (Figure 10a). At the beginning of stage iv, the value of $v_{P}$ had a stable trend as well. After the outlet pressure reached $26 \mathrm{MPa}$, massive fractures were generated leading to a weak decrease of $v_{P}$ value at all three paths. Finally, the $v_{P}$ value decreased by less than $1.5 \%(-0.05 \mathrm{~km} / \mathrm{s})$ during hydraulic fracturing. Therefore, the $v_{P}$ is not sensitive to the sample cracking. 


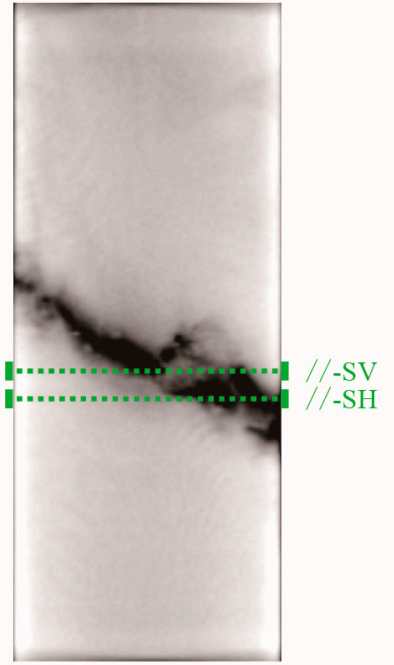

(a)

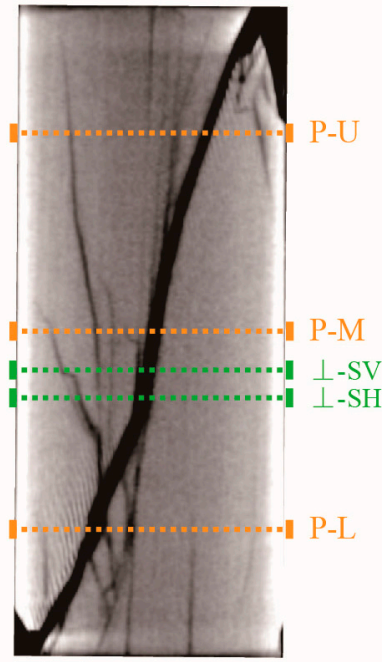

(b)

Figure 9. The relative position of $\mathrm{P} / \mathrm{S}$ wave paths with $\mathrm{CT}$ scanning slices. (a) Parallel with the bedding plane; (b) Vertical to bedding plane. The ray traces of ultrasonic $\mathrm{P}$ and $\mathrm{S}$ wave are indicated using orange and green dash lines respectively.

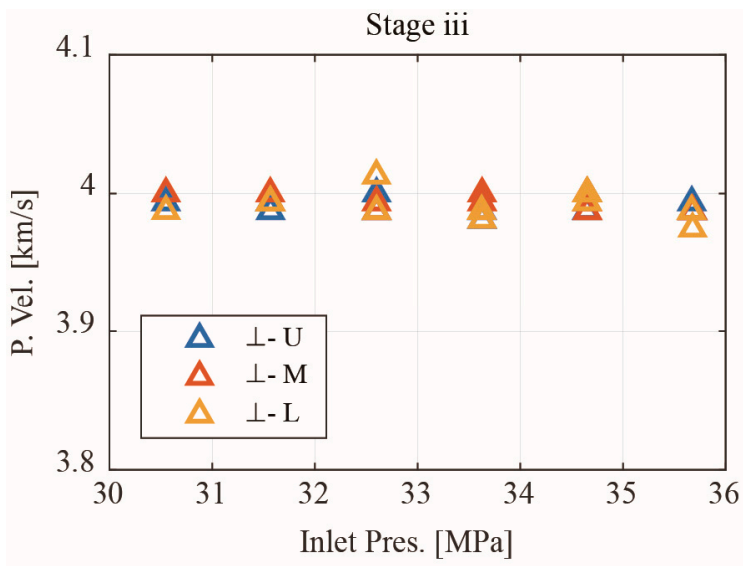

(a)

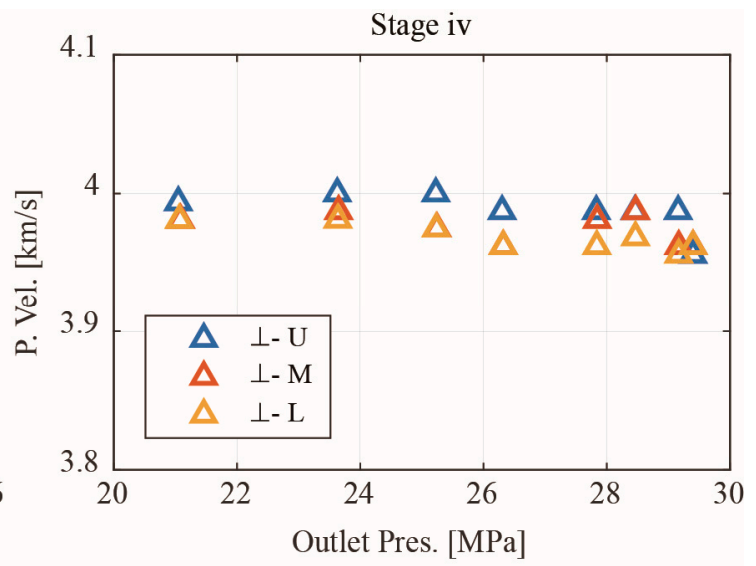

(b)

Figure 10. Comparison of measured $v_{P}$ in stage iii (a) and iv (b); $\perp-\mathrm{U}, \perp-\mathrm{M}$, and $\perp$-L indicates the wave traces at the upper, middle, and lower positions of the sample, respectively.

As regards the S-wave, the variation trend for velocity (Figure 11) is similar to the P-wave. The changes of $v_{/ /-S}$ and $v_{\perp-S}$ are examined here. Firstly, the $v_{/ /-S H}$ and $v_{/ /-S V}$ displayed a slight fluctuation $(2.85 \mathrm{~km} / \mathrm{s} \sim 2.92 \mathrm{~km} / \mathrm{s})$ in stage iii (Figure 11a,b), and the biggest amplitude of fluctuation was less than $1 \%$. This kind of fluctuation existed persistently when the outlet pressure was smaller than $26 \mathrm{MPa}$. Then a distinct descending trend appeared for the value of $v_{/ /-\mathrm{SH}}$ and $v_{/ /-\mathrm{SV}}$ following increasing outlet pressure. In the end, the $v_{/ /-S}$ decreased about $1.7 \%(-0.05 \mathrm{~km} / \mathrm{s})$ after hydraulic fracturing. Secondly, the $v_{\perp-S H}$ and $v_{\perp-S V}$ value began to decrease at the beginning of stage iii (Figure 11c,d). During the whole hydraulic fracturing procedure (stage iii and iv), there was a slight descending trend (smaller than $0.06 \mathrm{~km} / \mathrm{s}$ ) for the value of $v_{\perp-S}$. This phenomenon indicated that the original fracture had been gradually stimulated accompanied with increasing injection pressure. Finally, according to the statistical results, the variation range for all kinds of S-wave was less than $4 \%$. Comparing the changing characteristics of P- and S-wave velocities, we can conclude that the velocity sensitivity to hydraulic fracturing is relatively small. 


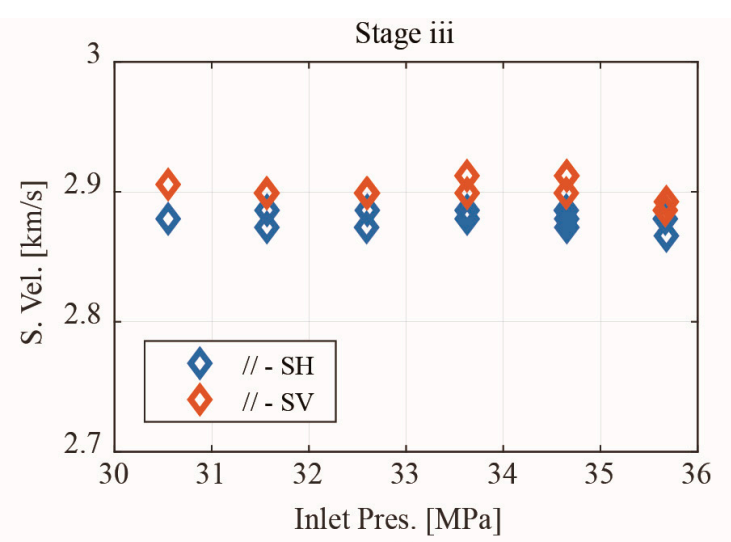

(a)

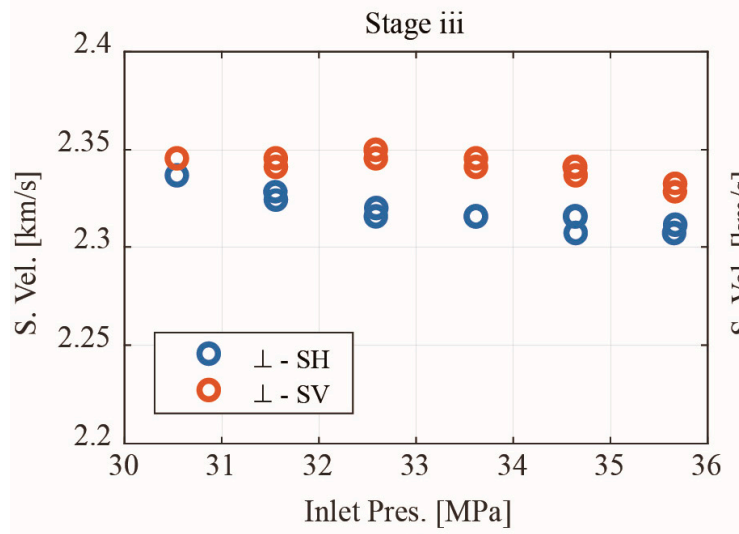

(c)

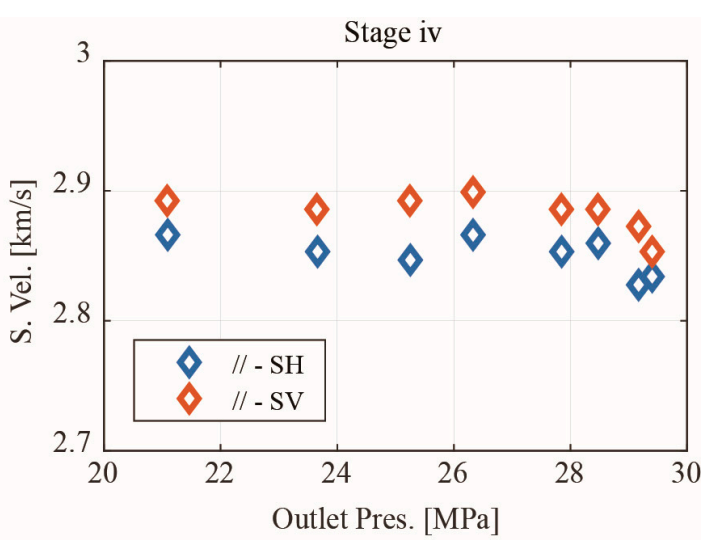

(b)

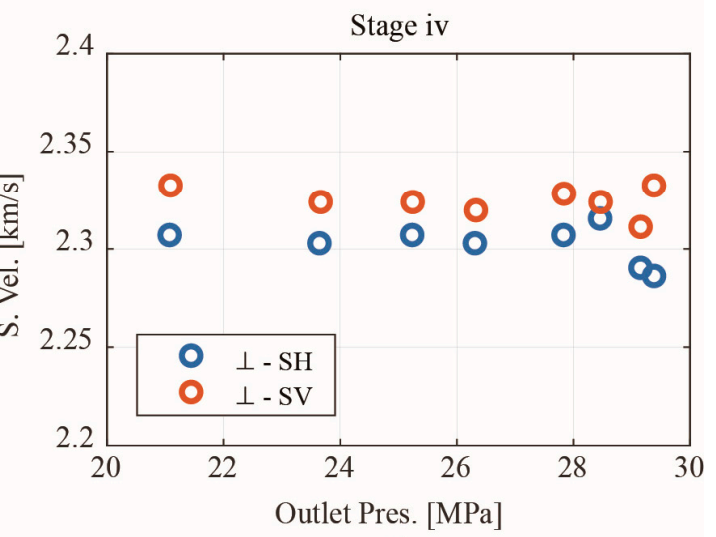

(d)

Figure 11. Comparison of measured $v_{/ /-S}$ and $v_{\perp-S}$ in stages iii and iv. (a) $v_{/ /-S H}$ and $v_{/ /-S V}$ in stage iii; (b) $v_{/ /-S H}$ and $v_{/ /-S V}$ in stage iv; (c) $v_{\perp-S H}$ and $v_{\perp-S V}$ in stage iii; (d) $v_{\perp-S H}$ and $v_{\perp-S V}$ in stage iv.

\subsection{Attenuation vs. Injection Pressure}

In the experiment, high-pressure water was injected into the sample from the beginning of stage $\mathrm{i}$. According to the injection rate monitored by pump B, we can explain that the initial fracture had not been closed completely when the confining pressure increased continuously. After long-time water injection, the preexisting fractures were saturated with water. But, the volume of injected water existing in the sample was very limited according to the recording of pump A and B. Moreover, the $Q_{P}^{-1}$ value at three measuring positions showed obvious differences (Figure 12). The $Q_{P}^{-1}$ value measured at the upper and lower parts of the sample $(\perp-\mathrm{U}$ and $\perp$-L, respectively) was very close, and had a similar increasing trend. Furthermore, the $Q_{P}^{-1}$ value measured at the central parts of the sample $(\perp-\mathrm{M})$ was almost three times larger than the others before the final complete rupture. This phenomenon indicated that the attenuation effect at the central parts of the sample was strongest and there was more water stored in this area.

Meanwhile, in Stage iii, the inlet injection pressure was gradually increased to $35 \mathrm{MPa}$ while the outlet pressure was kept constant at $20 \mathrm{MPa}$. From the monitored strain data (Figure $6 \mathrm{c}, \mathrm{e}$ ), we can conclude that the sample had been fracturing gradually. At last, the $Q_{\perp-P}^{-1}$ value had an increment of only $6.1 \%$ in the middle part of the sample but remained stable in the other two positions in this stage (Figure 12a). This result indicates that the $Q_{P}^{-1}$ value is undiscerning for shale-cracking when the rock is saturated with water. Compared with the variation of $v_{P}, v_{/ /-S}$ and $v_{\perp-S}$ in this stage, it is difficult to identify the generation of fractures only using the $Q_{\perp-P}^{-1}$ value. Then, in stage iv, the outlet pressure was increased rapidly from $20 \mathrm{MPa}$ to $28 \mathrm{MPa}$ followed by the final dynamic fracturing. The $Q_{\perp-P}^{-1}$ 
value kept a relatively stable value as well before the outlet pressure reached $28 \mathrm{MPa}$ (Figure 12b). When the outlet pressure was continuously increasing, the $Q_{\perp-P}^{-1}$ value displayed a sudden ascending due to the wholescale failure of the sample which could be identified as well from the monitored strain data. At last, the sudden increment of the $Q_{\perp-P}^{-1}$ value from the upper to the lower position was about $22.7 \%, 34.7 \%$, and $53.5 \%$, respectively. Overall, the $Q_{\perp-P}^{-1}$ value is relatively more sensitive than $P$ - and S-wave velocity to identify rock cracking. However, there is insensitivity as well for the $Q_{\perp-P}^{-1}$ value when the fractures are saturated with water.

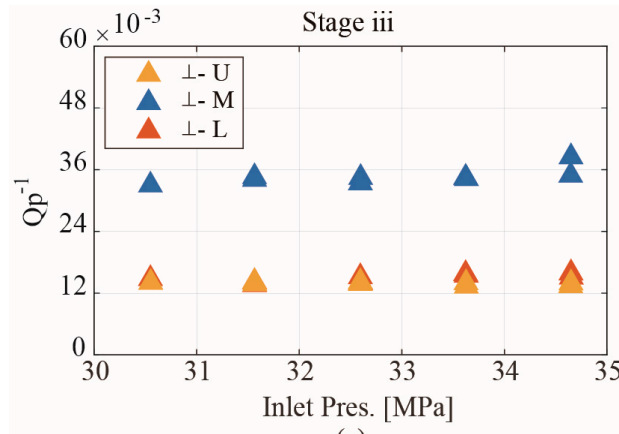

(a)

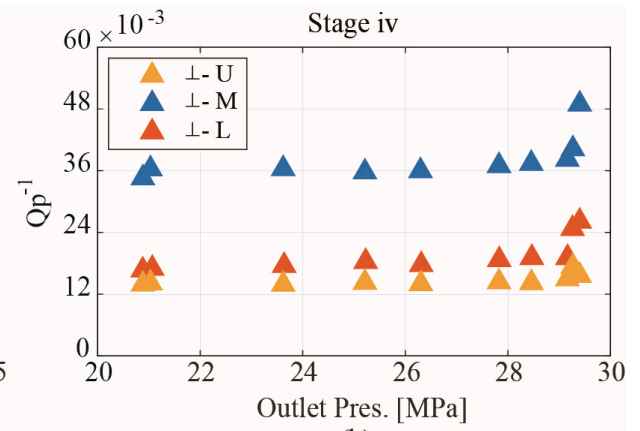

(b)

Figure 12. Comparison of measured $Q_{\perp-P}^{-1}$ in stage iii (a) and iv (b), respectively.

On the other hand, the $Q_{/ /-S}^{-1}$ value and $Q_{\perp-S}^{-1}$ value displayed a similar variation tendency during the final two stages (Figures 13 and 14). Firstly, unlike the $Q_{\perp-P}^{-1}$ value, the increment of the $Q_{S}^{-1}$ value appeared to be obvious and tended to increase from the beginning of stage iii. There were little differences in the change of $Q_{S}^{-1}$ value along two kinds of travel direction. For the //-S wave, the increment of the $Q_{/ /-S H}^{-1}$ and $Q_{/ /-S V}^{-1}$ value was about $24.1 \%$ and $50 \%$ (Figure 13a), respectively. However, for the $\perp-S$ wave, the increment of $Q_{\perp-S H}^{-1}$ (about 15.4\%) was apparently smaller than the ascending of the $Q_{/ /-S}^{-1}$ value (Figure 13b). The $Q_{\perp-S V}^{-1}$ value only displayed a slight fluctuation in this stage. Therefore, compared with the variation of $Q_{\perp-P}^{-1}$ value, we can monitor the hydraulic fracturing more precisely by utilizing the $Q_{/ /-S}^{-1}$ value.

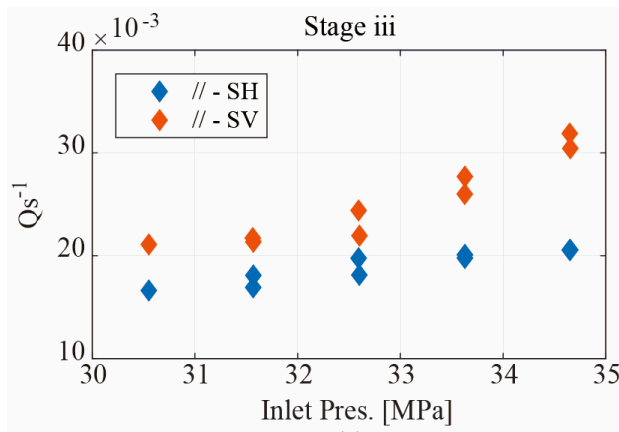

(a)

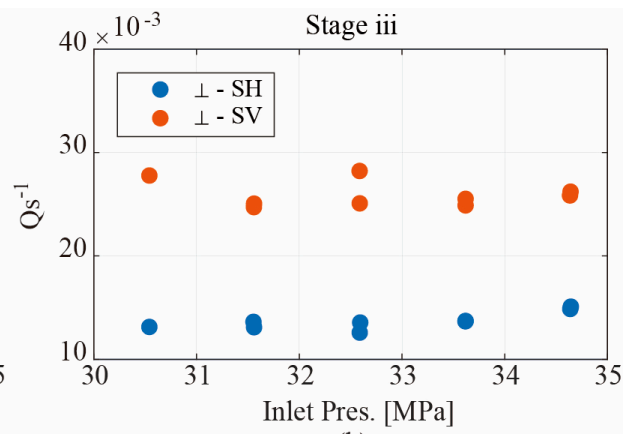

(b)

Figure 13. Comparison of measured $Q_{/ /-S}^{-1}(\mathbf{a})$ and $Q_{\perp-S}^{-1}(\mathbf{b})$ in stage iii, respectively.

Secondly, during the main hydraulic fracturing procedure (stage iv), a similar pattern was obtained for the $Q_{S}^{-1}$ value. There were two types of ascending rate for the $Q_{S H}^{-1}$ value before and after outlet pressure larger than $28 \mathrm{MPa}$ (Figure 14). When the outlet pressure from pump B ascended from $20 \mathrm{MPa}$ to $28 \mathrm{MPa}$, the increment of the $Q_{/ /-S H}^{-1}$ and $Q_{\perp-S H}^{-1}$ value was about $107 \%$ and $55.8 \%$, respectively. This indicated that more and more fractures had been generated. Then, the $Q_{S H}^{-1}$ value increased rapidly after outlet pressure reached $28 \mathrm{MPa}$. There was a significant increment (about 
two times) for the $Q_{S H}^{-1}$ value during a short period at the end of this stage. For $Q_{/ /-S V}^{-1}$ and $Q_{\perp-S V}^{-1}$ value, the increment rate was relatively small (about $13.8 \%$ and $47.3 \%$ respectively) during the whole of stage iv. Moreover, for $Q_{S V}^{-1}$ value, there was no steep increasing at the end of stage iv. Ultimately, we can conclude that the $Q_{S H}^{-1}$ value is more sensitive than $Q_{\perp-P}^{-1}$ and $Q_{S V}^{-1}$ to identify fracture status, especially in the final rapid fracturing procedure.

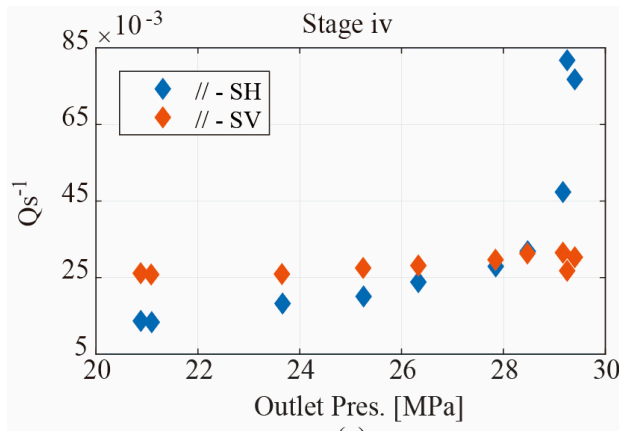

(a)

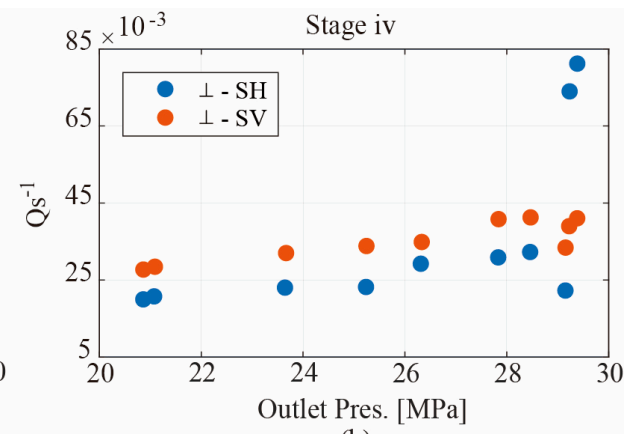

(b)

Figure 14. Comparison of measured $Q_{/ /-S}^{-1}(\mathbf{a})$ and $Q_{\perp-S}^{-1}(\mathbf{b})$ in stage iv, respectively.

\subsection{Discussion}

According to the above analysis, we can summarize the percentage change of velocity and attenuation for ultrasonic P- and S-waves. As Tables 1 and 2 show, the velocity and attenuation of P- and S-waves have different sensitivities during the dynamic hydraulic fracturing process. Firstly, the maximum decreasing percentage of velocity is only $-2.1 \%\left(v_{\perp-S H}\right)$ after the sample completely fracturing. When processing field microseismic data, it is easy to ignore this kind of decrease. However, the attenuation value is more sensitive than the velocity value during hydraulic fracturing, and the increasing percentage of $Q^{-1}$ exhibits multiple variation values (22.8 520.8\%) for different travel paths and waveforms. Secondly, the changes of $Q_{S}^{-1}$ value are more dynamic than $Q_{P}^{-1}$ value, especially in stage iii. This phenomenon indicates that the variation of $Q_{S}^{-1}$ value is a better index for identifying fracture growth and development. Finally, the $Q_{S H}^{-1}$ value shows an extraordinary increase $(391.9 \%$ \& $520.8 \%$ ) along two traveling paths $(/ / \& \perp)$ when the sample suffered a complete cracking. Comparing with the changes of the $Q_{S V}^{-1}$ values $(43.7 \% \& 47.3 \%)$, we can conclude that the orientation of fractures is a dominant factor for $S$-wave attenuation. The findings of this study indicate that a dynamic attenuation model is necessary for microseismic data processing and inversion. If using the S-waveform, different attenuation models for $S V$ - and $S H$-waves must be carefully investigated.

Table 1. The percent change of P-wave velocity and attenuation during stage iii and iv.

\begin{tabular}{cccc}
\hline Percent Change & $\boldsymbol{P}_{\perp-U}$ & $\boldsymbol{P}_{\perp-M}$ & $\boldsymbol{P}_{\perp-L}$ \\
\hline$v(\%)$ & $-1.0^{1}$ & -0.9 & -0.6 \\
$Q^{-1}(\%)$ & 22.8 & 48.3 & 76.6 \\
\hline mol represents the velocity descended after hydraulic fracturing.
\end{tabular}

Table 2. The percent change of S-wave velocity and attenuation during stage iii and iv.

\begin{tabular}{ccccc}
\hline Percent Change & //- SH & /I- SV & $\perp-S H$ & $\perp-S V$ \\
\hline$v(\%)$ & $-1.8^{1}$ & -1.8 & -2.1 & -1.4 \\
$Q^{-1}(\%)$ & 391.9 & 43.7 & 520.8 & 47.3 \\
\hline $1{ }^{\prime}-$ ' symbol represents the velocity & descended after hydraulic fracturing.
\end{tabular}




\section{Conclusions}

The hydro-fracturing operation changed the physical properties of the shale sample significantly. Through the analysis of ultrasonic P/S waveforms, we determined the variation pattern of wave velocity and attenuation of the Longmaxi shale during the hydro-fracturing test. Firstly, the change of velocity can be neglected during hydraulic fracturing. However, the attenuation of shale, which increments are tens or hundreds of times larger than the velocity decrements, is acutely sensitive to the generation of fractures. Secondly, the P-wave attenuation will lose its sensitivity to water injection after the fractures are saturated with water. Before the sample finally suffers structural cracking, the maximum increase of the $Q_{\perp-P}^{-1}$ value is less than $10 \%$. In that case, it is preferable to use S-wave attenuation to identify the opening or closing of fractures. Furthermore, the changing of S-wave attenuation depends on the orientation of the fracture surface and the polarization direction, which can be verified from the variation difference of the $Q_{S H}^{-1}$ and $Q_{S V}^{-1}$ value. And it is easier to be influenced for the $\mathrm{SH}$-wave during the hydraulic fracturing procedure.

In this study, we paused the measurement of velocity and attenuation during the very short final rapid-cracking stage to ensure that $\mathrm{AE}$ monitoring could be performed without any interruption. Thus, more experiments are needed to investigate the specific change of the physical properties of $\mathrm{P}$ - and S-waves during the dynamic stage of hydraulic fracturing.

Acknowledgments: This research was supported by the Major Program of the National Natural Science Foundation of China [41390455] and the Chinese Academy of Sciences Frontier Key Research Project [QYZDY-SSW-DQC009].

Author Contributions: Each author has contributed to the present paper. $\mathrm{Xu} C$ hang conceived and directed the experiments; Hongyu Zhai, Yibo Wang, Xinglin Lei and Ziqiu Xue performed the experiments; Hongyu Zhai analyzed the data and wrote the paper; Yi Zhang contributed suggestions.

Conflicts of Interest: The authors declare no conflict of interest.

\section{References}

1. Kendall, M.; Maxwell, S.; Foulger, G.; Eisner, L.; Lawrence, Z. Microseismicity: Beyond dots in a box-Introduction. Geophysics 2011, 76, Wc1-Wc3. [CrossRef]

2. Song, F.; Warpinski, N.R.; Toksöz, M.N. Full-waveform based microseismic source mechanism studies in the barnett shale: Linking microseismicity to reservoir geomechanics. Geophysics 2014, 79, KS13-KS30. [CrossRef]

3. Du, J.; Warpinski, N.R. Uncertainty in fpss from moment-tensor inversion. Geophysics 2011, 76, Wc65-Wc75. [CrossRef]

4. Liu, Y.; Dong, N.; Fehler, M.; Fang, X.; Liu, X. Estimating the fracture density of small-scale vertical fractures when large-scale vertical fractures are present. J. Geophys. Eng. 2015, 12, 311. [CrossRef]

5. Yang, Y.; Zoback, M.D. The role of preexisting fractures and faults during multistage hydraulic fracturing in the bakken formation. Interpretation 2014, 2, SG25-SG39. [CrossRef]

6. Amalokwu, K.; Best, A.I.; Sothcott, J.; Chapman, M.; Minshull, T.; Li, X.Y. Water saturation effects on elastic wave attenuation in porous rocks with aligned fractures. Geophys. J. Int. 2014, 197, 943-947. [CrossRef]

7. Bardainne, T.; Gaucher, E. Constrained tomography of realistic velocity models in microseismic monitoring using calibration shots. Geophys. Prospect. 2010, 58, 739-753. [CrossRef]

8. Vavrycuk, V. On the retrieval of moment tensors from borehole data. Geophys. Prospect. 2007, 55, 381-391. [CrossRef]

9. Eaton, D.W.; van der Baan, M.; Birkelo, B.; Tary, J.B. Scaling relations and spectral characteristics of tensile microseisms: Evidence for opening/closing cracks during hydraulic fracturing. Geophys. J. Int. 2014, 196, 1844-1857. [CrossRef]

10. Grechka, V.; Yaskevich, S. Azimuthal anisotropy in microseismic monitoring: Part 1-Theory. In Seg Technical Program Expanded Abstracts 2013; Society of Exploration Geophysicists: Houston, TX, USA, 2013; pp. 1987-1991. 
11. Grechka, V.; Yaskevich, S. Azimuthal anisotropy in microseismic monitoring: Part 2-Case study. In Seg Technical Program Expanded Abstracts 2013; Society of Exploration Geophysicists: Houston, TX, USA, 2013; pp. 1992-1997.

12. Tselentis, G.A.; Paraskevopoulos, P.; Martakis, N. Intrinsic qp seismic attenuation from the rise time of microearthquakes: A local scale application at rio-antirrio, western greece. Geophys. Prospect. 2010, 58, 845-859. [CrossRef]

13. Toksoz, M.N.; Johnston, D.H.; Timur, A. Attenuation of seismic waves in dry and saturated rocks; i, laboratory measurements. Geophysics 1979, 44, 681-690. [CrossRef]

14. Xue, Z.; Lei, X. Laboratory study of co2 migration in water-saturated anisotropic sandstone, based on p-wave velocity imaging. Explor. Geophys. 2006, 37, 10-18. [CrossRef]

15. Lei, X.; Xue, Z. Ultrasonic velocity and attenuation during $\mathrm{CO}_{2}$ injection into water-saturated porous sandstone: Measurements using difference seismic tomography. Phys. Earth Planet. Inter. 2009, 176, $224-234$. [CrossRef]

16. Zhang, Y.; Nishizawa, O.; Kiyama, T.; Xue, Z. Saturation-path dependency of p-wave velocity and attenuation in sandstone saturated with $\mathrm{CO}_{2}$ and brine revealed by simultaneous measurements of waveforms and X-ray computed tomography images. Geophysics 2015, 80, D403-D415. [CrossRef]

17. Ekanem, A.M.; Wei, J.; Li, X.Y.; Chapman, M.; Main, I.G. P-wave attenuation anisotropy in fractured media: A seismic physical modelling study. Geophys. Prospect. 2013, 61, 420-433. [CrossRef]

18. Luan, X.; Di, B.; Wei, J.; Zhao, J.; Li, X. Creation of synthetic samples for physical modelling of natural shale. Geophys. Prospect. 2016, 64, 898-914. [CrossRef]

19. Shi, B.; Murakami, Y.; Wu, Z.; Chen, J.; Inyang, H. Monitoring of internal failure evolution in soils using computerization x-ray tomography. Eng. Geol. 1999, 54, 321-328. [CrossRef]

20. Yun, T.S.; Jeong, Y.J.; Kim, K.Y.; Min, K.-B. Evaluation of rock anisotropy using 3d X-ray computed tomography. Eng. Geol. 2013, 163, 11-19. [CrossRef]

21. Li, X.; Lei, X.; Li, Q.; Li, X. Experimental investigation of sinian shale rock under triaxial stress monitored by ultrasonic transmission and acoustic emission. J. Nat. Gas Sci. Eng. 2017, 43, 110-123. [CrossRef]

22. Rybacki, E.; Reinicke, A.; Meier, T.; Makasi, M.; Dresen, G. What controls the mechanical properties of shale rocks? - part i: Strength and young's modulus. J. Pet. Sci. Eng. 2015, 135, 702-722. [CrossRef]

23. Rybacki, E.; Meier, T.; Dresen, G. What controls the mechanical properties of shale rocks?-Part ii: Brittleness. J. Pet. Sci. Eng. 2016, 144, 39-58. [CrossRef]

24. Hsu, S.C.; Nelson, P.P. Characterization of eagle ford shale. Eng. Geol. 2002, 67, 169-183. [CrossRef]

25. Zadeh, M.K.; Mondol, N.H.; Jahren, J. Velocity anisotropy of upper jurassic organic-rich shales, norwegian continental shelf. Geophysics 2017, 82, C61-C75. [CrossRef]

26. Kuila, U.; Dewhurst, D.; Siggins, A.; Raven, M. Stress anisotropy and velocity anisotropy in low porosity shale. Tectonophysics 2011, 503, 34-44. [CrossRef]

27. Josh, M.; Esteban, L.; Delle Piane, C.; Sarout, J.; Dewhurst, D.N.; Clennell, M.B. Laboratory characterisation of shale properties. J. Pet. Sci. Eng. 2012, 88-89, 107-124. [CrossRef]

28. Delle Piane, C.; Sarout, J.; Madonna, C.; Saenger, E.H.; Dewhurst, D.N.; Raven, M. Frequency-dependent seismic attenuation in shales: Experimental results and theoretical analysis. Geophys. J. Int. 2014, 198, 504-515. [CrossRef]

29. Zhubayev, A.; Houben, M.E.; Smeulders, D.M.J.; Barnhoorn, A. Ultrasonic velocity and attenuation anisotropy of shales, whitby, united kingdom. Geophysics 2015, 81, D45-D56. [CrossRef]

30. Tutuncu, A.N.; Katsuki, D.; Bui, B.T.; Padin, A.; McDowell, B. Coupling geomechanics and petrophysical measurements for production enhancement in organic-rich shales. In Proceedings of the Unconventional Resources Technology Conference, San Antonio, TX, USA, 1-3 August 2016; pp. 3308-3325.

31. Bui, B.T.; Tutuncu, A.N. Contribution of osmotic transport on oil recovery from rock matrix in unconventional reservoirs. J. Pet. Sci. Eng. 2017, 157, 392-408. [CrossRef]

32. Katsuki, D.; Tutuncu, A.N. Coupling Complex Resistivity, Geomechanical and Acoustic Properties and Permeability in Sandstone and Shale Reservoirs. In Proceedings of the Unconventional Resources Technology Conference (URTEC), San Antonio, TX, USA, 24-26 July 2017.

33. Chen, S.; Zhu, Y.; Qin, Y.; Wang, H.; Liu, H.; Fang, J. Reservoir evaluation of the lower silurian longmaxi formation shale gas in the southern sichuan basin of china. Mar. Pet. Geol. 2014, 57, 619-630. [CrossRef] 
34. Liu, S.; Ma, W.; Jansa, L.; Huang, W.; Zeng, X.; Zhang, C. Characteristics of the shale gas reservoir rocks in the lower silurian longmaxi formation, east sichuan basin, china. Energy Explor. Exploit. 2013, 31, 187-219. [CrossRef]

35. Guo, X.; Li, Y.; Liu, R.; Wang, Q. Characteristics and controlling factors of micropore structures of the longmaxi shale in the jiaoshiba area, sichuan basin. Nat. Gas Ind. B 2014, 1, 165-171. [CrossRef]

36. Ma, Y.; Pan, Z.; Zhong, N.; Connell, L.D.; Down, D.I.; Lin, W.; Zhang, Y. Experimental study of anisotropic gas permeability and its relationship with fracture structure of longmaxi shales, sichuan basin, china. Fuel 2016, 180, 106-115. [CrossRef]

37. Liang, C.; Jiang, Z.; Zhang, C.; Guo, L.; Yang, Y.; Li, J. The shale characteristics and shale gas exploration prospects of the lower silurian longmaxi shale, sichuan basin, south china. J. Nat. Gas Sci. Eng. 2014, 21, 636-648. [CrossRef]

38. Jiao, K.; Yao, S.; Liu, C.; Gao, Y.; Wu, H.; Li, M.; Tang, Z. The characterization and quantitative analysis of nanopores in unconventional gas reservoirs utilizing fesem-fib and image processing: An example from the lower silurian longmaxi shale, upper yangtze region, china. Int. J. Coal Geol. 2014, 128-129, 1-11. [CrossRef]

39. Yang, R.; He, S.; Yi, J.; Hu, Q. Nano-scale pore structure and fractal dimension of organic-rich wufeng-longmaxi shale from jiaoshiba area, sichuan basin: Investigations using fe-sem, gas adsorption and helium pycnometry. Mar. Pet. Geol. 2016, 70, 27-45. [CrossRef]

40. Deng, J.; Shen, H.; Xu, Z.; Ma, Z.; Zhao, Q.; Li, C. Dynamic elastic properties of the wufeng-longmaxi formation shale in the southeast margin of the sichuan basin. J. Geophys. Eng. 2014, 11, 035004. [CrossRef]

41. Wu, Y.; Lan, H.; Gao, X.; Wang, W.; Chen, J.; Hao, S. The relationship between the volume density of cracks and acoustic properties of the shale core samples from fulin. Chin. J. Geophys. 2016, 59, 3891-3900.

42. Lei, X.; Kusunose, K.; Rao, M.; Nishizawa, O; Satoh, T. Quasi-static fault growth and cracking in homogeneous brittle rock under triaxial compression using acoustic emission monitoring. J. Geophys. Res. 2000, 105, 6127-6139. [CrossRef]

43. Johnston, D.H.; Toksoz, M.; Timur, A. Attenuation of seismic waves in dry and saturated rocks; ii, mechanisms. Geophysics 1979, 44, 691-711. [CrossRef]

(C) 2017 by the authors. Licensee MDPI, Basel, Switzerland. This article is an open access article distributed under the terms and conditions of the Creative Commons Attribution (CC BY) license (http:/ / creativecommons.org/licenses/by/4.0/). 